\title{
Cowhage-Evoked Itch Is Mediated by a Novel Cysteine Protease: A Ligand of Protease-Activated Receptors
}

\author{
Vemuri B. Reddy, ${ }^{1}$ Aurel 0. Iuga, ${ }^{1}$ Steve G. Shimada, ${ }^{2}$ Robert H. LaMotte, ${ }^{2}$ and Ethan A. Lerner ${ }^{1}$ \\ ${ }^{1}$ Cutaneous Biology Research Center, Department of Dermatology, Massachusetts General Hospital, Charlestown, Massachusetts 02129, and ${ }^{2}$ Department \\ of Anesthesiology, Yale University School of Medicine, New Haven, Connecticut 06520
}

Cowhage spicules provide an important model for histamine-independent itch. We determined that the active component of cowhage, termed mucunain, is a novel cysteine protease. We isolated mucunain and demonstrate that both native and recombinant mucunain evoke the same quality of itch in humans. We also show that mucunain is a ligand for protease-activated receptors two and four. These results support and expand the relationship between proteases, protease-activated receptors, and itch.

Key words: pruritus; cowhage; Mucuna pruriens; cysteine protease; protease-activated receptor; receptor

\section{Introduction}

Itch, a relatively uninvestigated yet elemental sensory modality separate from others, is a distressing symptom of many systemic, parasitic, and cutaneous diseases. Although most experimental studies of itch use histamine as the pruritic stimulus (Simone et al., 1987; Schmelz et al., 1997; Atanassoff et al., 1999), clinical pruritus is not typically mediated by histamine (Klein and Clark, 1999; Steinhoff et al., 2003). Therefore, the identification of compounds that elicit a strong histamine-independent itch would provide a tool with which to search for novel itch receptors and endogenous ligands.

The pods of cowhage (Mucuna pruriens), an annual climbing legume found widely in tropical areas, are covered with small spicules or trichomes known to evoke intense pruritus. Insertion of a single cowhage spicule or multiple spicules (see Fig. 1a) into the superficial skin produces itching. This itching may be accompanied by localized erythema and edema of a few millimeters but a flare or wheal does not occur (Johanek et al., 2007). The response to the active component is not considered allergic, because pruritus is noted after first exposure. Nociceptive qualities such as pricking/stinging and burning also typically occur (Masood et al., 2005; Shimada et al., 2006). The active substance thus elicits pruritus and, to some degree, pricking/stinging and burning, without the urticarial response associated with histamine. These observations suggest that the mediator of itch from this plant could identify a nonhistamine pathway of pruritus. Cow-

Received Feb. 15, 2008; revised March 13, 2008; accepted March 17, 2008.

This work was supported in part by a Clinical and Translational Science Award, National Center for Research Resources (NCRR) Grant UL1 RR0249139 [a component of the National Institutes of Health (NIH)], NIH Grant P01 NS 047300 (R.H.L., PI), and an agreement between Massachusetts General Hospital and Shiseido (Tokyo, Japan). Psychophysical experiments were approved by the Yale University Human Investigation Committee. The contents of this publication are solely the responsibility of the authors and do not necessarily represent the official view of NCRR or NIH. We thank Jessica Zvara, Kristine Kenning, Parul Sikand, Barry Green, and Kounga Kounga for their input and technical assistance.

Correspondence should be addressed to Ethan A. Lerner, Cutaneous Biology Research Center, Massachusetts General Hospital, Building 149, 13th Street, Charlestown, MA 02129. E-mail: elerner@partners.org.

DOI:10.1523/JNEUROSCI.0716-08.2008

Copyright $\odot 2008$ Society for Neuroscience $\quad$ 0270-6474/08/284331-05\$15.00/0 hage activates subpopulations of nociceptive neurons in cat and monkey (Tuckett and Wei, 1987; Johanek et al., 2005; Davidson et al., 2007). Despite early evidence that cowhage itch might be mediated by a protease called mucunain (Shelley and Arthur, 1955), neither the active component has been isolated nor has its signaling pathway been established. We set out to identify the itch-inducing component and determine its mechanism of action.

\section{Materials and Methods}

Chemicals. Papain was obtained from Sigma-Aldrich (St. Louis, MO) (product number P 4762). E64 (Barrett et al., 1982), a cysteine protease inhibitor, was also obtained from Sigma-Aldrich (product number E 3132). Stock solutions of $430 \mu \mathrm{M}$ papain and $1 \mathrm{~mm}$ E64, respectively, were prepared in PBS and diluted in the relevant assay buffers. Hexapeptide agonists of protease-activated receptors (PARs) were prepared at the peptide synthesis facility at Massachusetts General Hospital.

Protein extraction from spicules. Dry pods of $M$. pruriens were obtained from Costa Rica. The spicules were collected from the pods by shaking the pods in a closed bag. Ten grams of spicules were stirred at $4^{\circ} \mathrm{C}$ for $2 \mathrm{~h}$ in $300 \mathrm{ml}$ of a buffer containing $0.1 \mathrm{M} \mathrm{NaCl}$ and $0.01 \mathrm{M} \mathrm{L}$-cysteine, pH 5.7. This crude extract was passed through cheesecloth and then a $0.4 \mu \mathrm{M}$ filter. The extract was size-selected using centrifugal concentrators that had a molecular weight cutoff of $5 \mathrm{kDa}$ (Millipore Corporation, Billerica, MA). It was further purified using a P-60 column, and fractions were run on SDS-PAGE gels. The fraction showing a single prominent band at 36 $\mathrm{kDa}$ was subjected to additional analysis. This material is referred to as native mucunain and quantified using a noninterfering protein assay (Pierce, Rockford, IL). By counting the number of spicules in a small sample, the number of spicules per milligram was estimated. When combined with the quantization of protein, it was deduced that each spicule contained 4-12 ng of protein.

Protein sequencing. The protein band running at $36 \mathrm{kDa}$ was subjected to amino acid sequence analysis by tandem mass spectrometry on a Finnigan LCQ quadrupole ion trap mass spectrometer (Thermo Scientific, Waltham, MA). The protein was also subjected to $\mathrm{NH}_{2}$-terminal sequence analysis by Edman degradation.

Preparation of total RNA, poly-A RNA, and double-stranded cDNA. RNA was extracted from leaves and stems, because it was found that spicules did not contain workable quantities of RNA. Leaves and stems of 
M. pruriens were ground to a fine powder in liquid nitrogen, and total RNA was extracted using the QIAGEN (Valencia, CA) RNAeasy protocol. Poly-A RNA was isolated by the QIAGEN Oligotex procedure. The poly-A RNA was used as a template to make double-stranded (ds) cDNA using a cDNA preparation kit from Stratagene (La Jolla, CA).

Cloning of $\mathrm{M}$. pruriens cysteine protease $\mathrm{DNN}$ by $\mathrm{PCR}$. One microgram of ds cDNA was used as a template in a $50 \mu \mathrm{lPCR}$ volume using a forward primer, TGG GGC GCC AGC TGG GGY TTC GAG GGY TAY, based on the internal peptide, NSW GAS WGF EGY VR, and a reverse primer, $\mathrm{dT}_{28}$. The reaction containing pfu DNA polymerase from Stratagene was heated at $95^{\circ} \mathrm{C}$ for $5 \mathrm{~min}$ followed by 30 cycles of denaturation at $95^{\circ} \mathrm{C}$ for $30 \mathrm{~s}$, annealing at $55^{\circ} \mathrm{C}$ for $1 \mathrm{~min}$, extension at $68^{\circ} \mathrm{C}$ for $2 \mathrm{~min}$, and a final extension at $68^{\circ} \mathrm{C}$ for $10 \mathrm{~min}$. PCR products $>100 \mathrm{bp}$ in length were cloned into a Zero-blunt TOPO PCR vector (Invitrogen, Carlsbad, CA) and sequenced. A reverse primer, AGG ACA AAT TTA AGC ATT GCT GCA TTA TCT ACC (based on the C-terminal sequence near the poly-A tail), and a forward primer, GAT AAC TTG CCG GAA TCT GTT GAT TGG AG (based on the NH2 terminal peptide, DNL PES VDW RNE GAV LPC KS), were used to isolate the entire mature protein coding sequence of $1300 \mathrm{bp}$. The entire cDNA of $1600 \mathrm{bp}$ was later isolated using a forward primer, CAC GTG GCG GAG CGA CGA GGA GGT GAT GTC, based on the sequence containing the signal peptide, and the reverse primer at the $\mathrm{C}$ terminus, AGG ACA AAT TTA AGC ATT GCT GCA TTA TCT ACC.

Expression of M. pruriens cysteine protease in Escherichia coli. The cDNA (1300 bp) coding for the pro-region and the mature portion of the protease was cloned into the expression vector pTWIN1 (New England Biolabs, Ipswich, MA) containing the T7 promoter and lac I repressor. The vector, pTWIN1MUC1300, was transformed into ER2566. The cells growing in log phase were induced with $0.3 \mathrm{~mm}$ isopropyl- $\beta$-Dthiogalactopyranoside. The E. coli were harvested, suspended in $30 \mathrm{ml}$ of lysis buffer $(0.5 \mathrm{M} \mathrm{NaCl}, 0.02 \mathrm{M}$ Tris, $1 \mathrm{~mm}$ EDTA, pH 8.5), and lysed in a French press. The protein, present predominately in the insoluble fraction as inclusion bodies, was solubilized with $8 \mathrm{~m}$ urea and refolded in the presence of $0.5 \mathrm{M} \mathrm{NaCl}, 0.05 \mathrm{M}$ Tris, $\mathrm{pH} 8.5,0.7 \mathrm{M} \mathrm{L}$-arginine, $0.01 \mathrm{M}$ glutathione, $0.001 \mathrm{M}$ glutathione disulfide, and $0.005 \mathrm{M}$ EDTA as described (Hwang and Chung, 2002). The refolded pro-protease, or zymogen, was activated in the presence of $0.2 \mathrm{~m}$ sodium acetate, $\mathrm{pH} 4.0,0.005$ м DTT, and $0.005 \mathrm{~m}$ EDTA and incubated at $37^{\circ} \mathrm{C}$ for $30 \mathrm{~min}$. The recombinant protein was purified by Centricon Plus-70 concentrators with $30 \mathrm{kDa}$ molecular weight cutoffs and dialyzed extensively against 0.1 $\mathrm{M} \mathrm{NaCl}$ and $0.01 \mathrm{M} \mathrm{L-cysteine,} \mathrm{pH}$ 5.7. In the chromogenic and calcium studies below, higher concentrations of recombinant compared with native mucunain were used to achieve similar effects. In contrast, similar concentrations of recombinant and native mucunain used in the sensory studies achieved similar effects. A possible explanation for this discrepancy is that the recombinant protein folds more effectively in vivo than in vitro.

Chromogenic substrate assay. Native and recombinant mucunain protease activity were measured in a buffer containing $50 \mathrm{~mm}$ sodium acetate, pH 5.5, $2.5 \mathrm{~mm}$ EDTA, $2.5 \mathrm{~mm}$ DTT, and $250 \mu \mathrm{g} / \mathrm{mlZ}$-Phe-Arg-pNA (Bachem, King of Prussia, PA) as the chromogenic substrate. After adding protease, or protease and E64, the reaction was incubated at room temperature for $1 \mathrm{~h}$. Generation of the yellow product, p-nitroaniline, was assayed by measuring the absorbance at $405 \mathrm{~nm}$. Papain served as a control cysteine protease. E64 was used at a concentration of $10 \mu \mathrm{M}$. Experiments were performed in triplicate, and the error bars represent SD.

Reconstitution of spicules. Native spicules were inactivated by autoclaving for $1 \mathrm{~h}$ and reconstituted with native and recombinant mucunains in the presence or absence of the cysteine protease inhibitor E64. Typically, $50 \mathrm{mg}$ of inactivated spicules were mixed with $0.4 \mathrm{ml}$ of $1 \mathrm{mg}$ of native or recombinant mucunain in $0.1 \mathrm{M} \mathrm{NaCl}$ with $0.01 \mathrm{M} \mathrm{L}$-cysteine in a $2 \mathrm{ml}$ Microfuge tube, vortexed, dried in a Speed-vac for $2 \mathrm{~h}$ at room temperature, vortexed again, and transferred to a new tube. This second vortex step allowed for precipitated salt to be separated from the spicules. These spicules were then considered "reconstituted" with the protease alone. Spicules prepared in a similar manner, but with E64 diluted from the 1 mM stock solution to achieve the same concentration as mucunain, were considered reconstituted with the protease and the inhibitor. The use of $1 \mathrm{mg}$ of mucunain for reconstitution was determined after a series of reconstitutions using a range of quantities of mucunain and then reextraction. One milligram of mucunain resulted in $4 \mathrm{ng}$ of mucunain per spicule, approximating the natural situation, although the distribution of protein on the spicule would not necessarily match the native ones.

Psychophysical studies in humans. Protocols were approved by the Yale University Human Investigation Committee. A row of 10 cowhage spicules were lightly glued to the flattened end of a Weck-Cel (Medtronic, Jacksonville, FL) surgical spear, spaced at $1 \mathrm{~mm}$, and applied parallel to the surface of the skin at the midvolar forearm. This resulted in an average of seven spicules superficially inserted $\sim 0.2 \mathrm{~mm}$ into skin. Every $30 \mathrm{~s}$, subjects rated the magnitude of each of three qualities of sensation: itch, pricking/stinging, and burning using a scale that uses appropriately placed intensity descriptors of "none," "barely detectable," "weak," "moderate," "strong," "very strong," and at the top of the scale "the strongest sensation imaginable" (Bartoshuk et al., 2004). Voltages derived from each subject's movements of a computer mouse that controlled a cursor on a visual representation of this scale were converted to numbers between 0 and 100 and plotted for each quality at successive intervals of $30 \mathrm{~s}$ up to $20 \mathrm{~min}$ after the insertion of cowhage. Each of nine subjects received, in separate tests, five types of cowhage spicules: native cowhage spicules, heat-inactivated spicules that had been soaked in a solution of cowhage extract containing E64, or the same but without E64, and heat-inactivated spicules that had been soaked previously in a solution of recombinant mucunain containing E64, or the same but without E64. The subject and experimenter were blinded as to the type of spicule administered.

PAR activation observed by cytoplasmic calcium release. The four human PAR cDNAs were obtained from commercial sources and cloned into the pcDNA3.1(-) vector (Invitrogen). HeLa cells were transfected with $10 \mu \mathrm{g}$ of vector cDNA using Lipofectamine 2000 (Invitrogen) and cultured for $2 \mathrm{~d}$ in 96-well glass-bottom plates at 30,000 cells/well. Cells were loaded with fura- 2 as follows. The medium was aspirated and replaced with $100 \mu \mathrm{l}$ of complete DMEM containing $2 \mu \mathrm{M}$ fura-2 (Invitrogen) and kept at room temperature in the dark for $1 \mathrm{~h}$. The medium was again aspirated, and each well received $90 \mu \mathrm{l}$ of HEPES-buffered saline (20 mм HEPES, $115 \mathrm{~mm} \mathrm{NaCl}$, $5.4 \mathrm{~mm} \mathrm{KCl,} 2 \mathrm{~mm} \mathrm{CaCl}, 0.8 \mathrm{~mm} \mathrm{MgCl}_{2}$, $13.8 \mathrm{~mm}$ glucose, $\mathrm{pH}$ 7.4). Plates were observed using a Zeiss (Peabody, MA) Axiovert $200 \mathrm{M}$ microscope equipped with a filter wheel for monitoring excitation at 340 and $380 \mathrm{~nm}$. Responses to test agents, analyzed using Axiovision software, version 4.6, were expressed as emission ratios of 340:380, which are proportionate to intracellular calcium. Ten microliters of protease or hexapeptide were applied $\sim 20 \mathrm{~s}$ after the start of excitation. For experiments that included E64, this inhibitor and mucunain were incubated together on ice for $5 \mathrm{~min}$ before application to the cells. Images were taken every $5 \mathrm{~s}$, beginning at time 0 , for $3 \mathrm{~min}$. The software was used to analyze the 37 images taken during the 3 min period.

\section{Results}

\section{A cysteine protease is a component of spicules from M. pruriens}

A series of natural product isolation experiments was undertaken to examine the presence of small molecules and proteins in the spicules scraped or shaken from dried pods collected from Costa Rica. Aqueous or organic solvents were used to extract material from spicules. The extracts were subjected to thin layer, size exclusion, anion exchange, or reversed phase chromatography. Fractions were then analyzed for chemical components by mass spectrometry and gel electrophoresis. Of nine components identified, two were pursued for additional study. One was a low molecular weight compound with a mass of $441 \mathrm{Da}$ consistent with folic acid, a known plant component but not a substance implicated in itch. The other was a $36 \mathrm{kDa}$ protein obtained from aqueous extracts (Fig. 1b). This protein was subsequently found to evoke itch in human volunteers as described below. Oligonucleotides, designed from the examination of $\mathrm{N}$-terminal and in- 
a

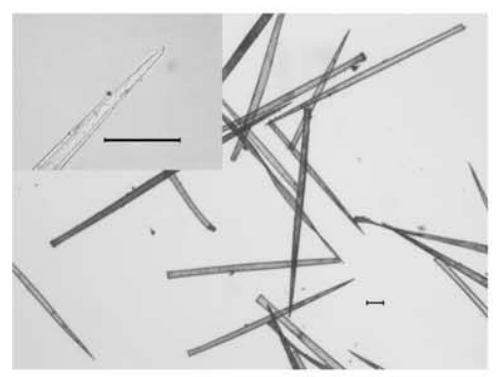

b

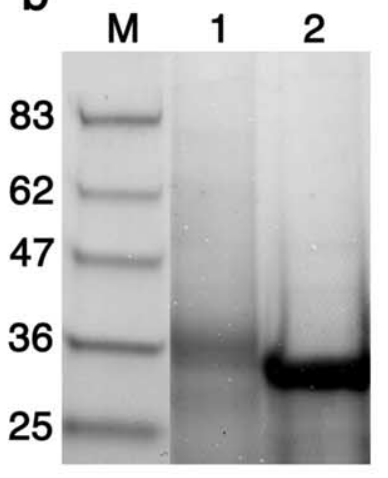

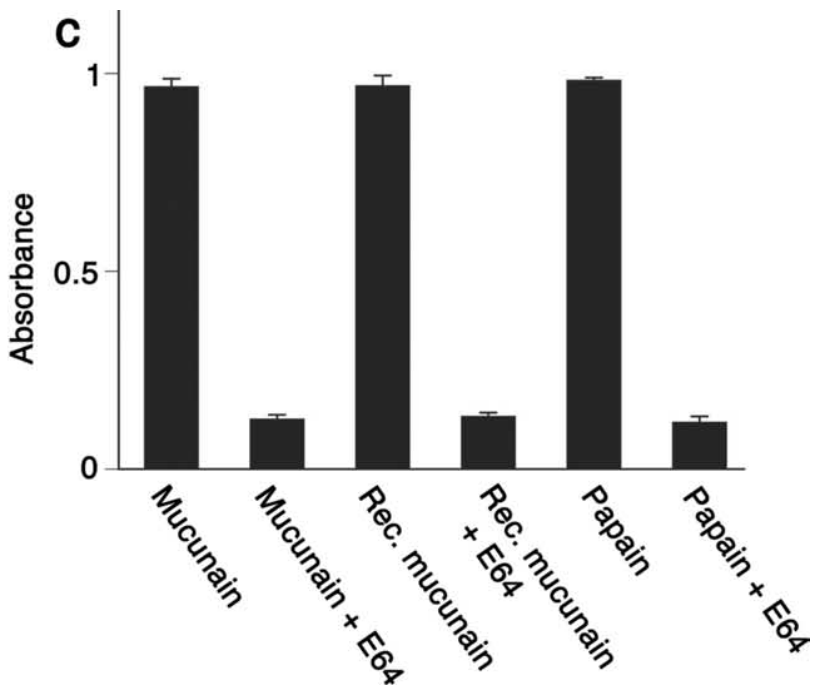

Figure 1. Photomicrograph of M. pruriens spicules and biochemical analysis of mucunain. $\boldsymbol{a}$, Photomicrograph of native spicules. Each spicule is $2-3 \mathrm{~mm}$ in length and typically one or a few micrometers in diameter at the tip. Scale bar, $100 \mu \mathrm{m}$. $\boldsymbol{b}$, SDS-PAGE of M. pruriens extract (lane 1) and recombinant mucunain (lane 2). The native protein may undergo posttranslational modification and thus run more slowly than the recombinant protein under reducing conditions. Molecular weight markers (kDa) are shown on the left.c, Mucunain cleaves the chromogenic substrate Z-FR-pNA, the cleavage of which was blocked by the protease inhibitor E64. Papain served as a positive control. The proteases were used at the following concentrations: native mucunain, $0.9 \mu \mathrm{m}$; recombinant mucunain, $2.7 \mu \mathrm{m}$; and papain, $4.3 \mu \mathrm{m}$. Experiments were performed in triplicate, and error bars represent SD.
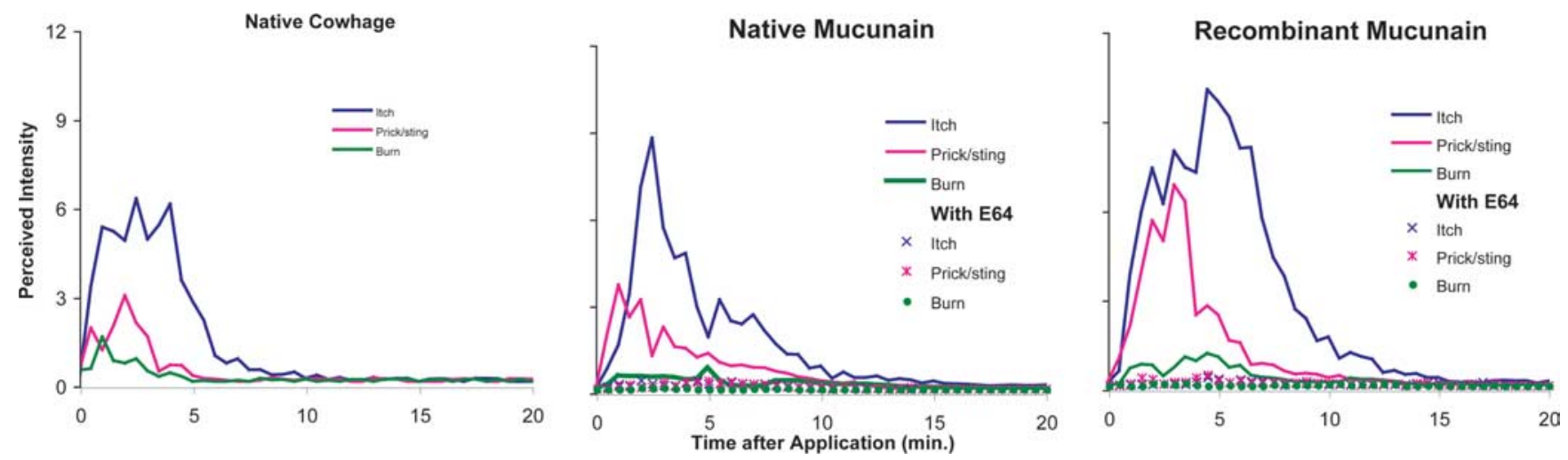

Figure 2. Perceived intensities of sensations evoked by native spicules and spicules reconstituted with native or recombinant mucunain. For each quality of sensation, the geometric mean of the ratings of nine subjects is plotted as a function of time after spicule insertion. Mucunain evoked itch (blue) and nociceptive sensations consisting of burning (green) and/or pricking/stinging (pink). Addition of E64 during reconstitution produced spicules that did not evoke significant itch or nociceptive sensations. Autoclaved spicules elicited no sensations after insertion into the skin (data not shown). Statistical comparisons were made of the treatments (native, extract, and recombinant mucunain) and sensory qualities (itch, prick/sting, and burn). For each subject, sensory quality, and treatment, the area under the curve plotting the natural log of the original rating versus time was obtained. The log of the lowest value possible on the scale was substituted for any rating of zero. A two-way, repeated-measures ANOVA of the mean areas for sensory quality versus treatment revealed a significant effect of quality $(p<0.0001)$, but no significant differences resulting from treatment $(p>0.05)$.

ternal amino acid sequences, were used in PCRs to obtain the full-length cDNA (supplemental material, available at www. jneurosci.org). To obtain cDNA, RNA that had been extracted from leaves and stems was used to isolate poly-A RNA, which was then used as a template to obtain cDNA. The full-length cDNA was used to express recombinant protein. Analysis of determined and deduced amino acid sequences and nucleotide sequences were consistent with the protein being a cysteine protease. The deduced amino acid sequence predicts a 20-residue signal peptide, a pro-region of 70 residues that constitutes the inactive zymogen portion, and a mature protein of 332 amino acids with a predicted mass of $36 \mathrm{kDa}$. We apply the word mucunain to this protein, a term used by Shelley and Arthur (1955) in the description of a pruritus-inducing extract from cowhage.

To determine whether the activity of mucunain was consistent with cysteine and serine proteases, the capacity for the native and recombinant proteins to cleave Z-FR-pNA, a chromogenic sub- strate of these proteases was evaluated (Fig. 1c). To distinguish between cysteine and serine protease activity, E64, a small molecule irreversible inhibitor of cysteine proteases, was used in the chromogenic assay. E64 blocked the protease activity, consistent with mucunain being a cysteine protease as predicted by sequence analysis.

\section{Sensory effects of mucunain}

Native cowhage spicules produced itch typically accompanied by lesser magnitudes of pricking/stinging and burning (Fig. 2, left). We sought a similar method of applying to the skin mucunain isolated from cowhage or recombinant mucunain without the possible interference of pain or injury from the use of conventional spicules. Cowhage spicules were first autoclaved for $1 \mathrm{~h}$ to inactivate native protein, subsequently soaked in a solution containing native or recombinant mucunain, and then dried. Other spicules were prepared in the same way but with solutions con- 
taining E64. The insertion of these reconstituted spicules in the skin of volunteers mimicked the sensations of itch, pricking/ stinging, and burning of the native spicules (Fig. 2, middle, right). There were no significant differences, because of the type of spicule (cowhage vs native or recombinant mucunain), in the areas under the rating curves for a given quality of sensation (Fig. 2). E64 blocked all sensations evoked by spicules containing native or recombinant mucunain. These results are consistent with mucunain being the only itch-inducing component of native spicules as well as accounting for the accompanying sensations of pricking/stinging and burning.

\section{Mucunain activates PAR2 and PAR4}

We next sought to determine the receptor through which mucunain signals. We hypothesized, for several reasons, that mucunain might activate a PAR. First, these receptors are activated by proteases. Second, mast cell tryptase, a serine protease that can cause itch, activates PAR2 (Steinhoff et al., 2003). Third, papain is a cysteine protease known to cause itch (Arthur and Shelley, 1955), although its signaling has not been examined. Fourth, the dust mite cysteine protease der $\mathrm{p} 1$, implicated in allergy, has the potential to signal through PAR2 (Kauffman et al., 2006). Finally, gingipains, which are cysteine proteases produced by bacteria associated with gingivitis, activate PAR1 and PAR4 (Lourbakos et al., 2001).

PAR signaling is complex but is known to include Gq, the activation of which can be followed via calcium mobilization. The activity of mucunain on individual PARs was evaluated. cDNAs encoding each of the four PARs were transfected transiently into HeLa cells. The cells were loaded with fura-2, and ratiometric calcium imaging was obtained after incubation with native mucunain or recombinant mucunain. The mean peak responses are shown in Figure $3 a$, and those for single-cell imaging are shown in Figure $3 b$ (native mucunain) and Figure $3 c$ (recombinant mucunain). Both native and recombinant mucunain were found to activate PAR2 and PAR4. The activation of PAR2 and PAR4 by mucunain was blocked completely by E64, yet these cells remained responsive to ionomycin (data not shown). Mucunain did not activate PAR1 or PAR3. Individual hexapeptide tethered ligands for each PAR served as controls. Therefore, SLIGRL activated PAR2 but not PAR4, whereas AYPGKF activated PAR4 but not PAR2. SFLLRN and TFRGAP activated PAR1 and PAR3, respectively, consistent with functional activity of these transfected PARs.

\section{Discussion}

Cowhage is the name given to the trichomes or spicules that cover the pods of $M$. pruriens, which have long been known to evoke
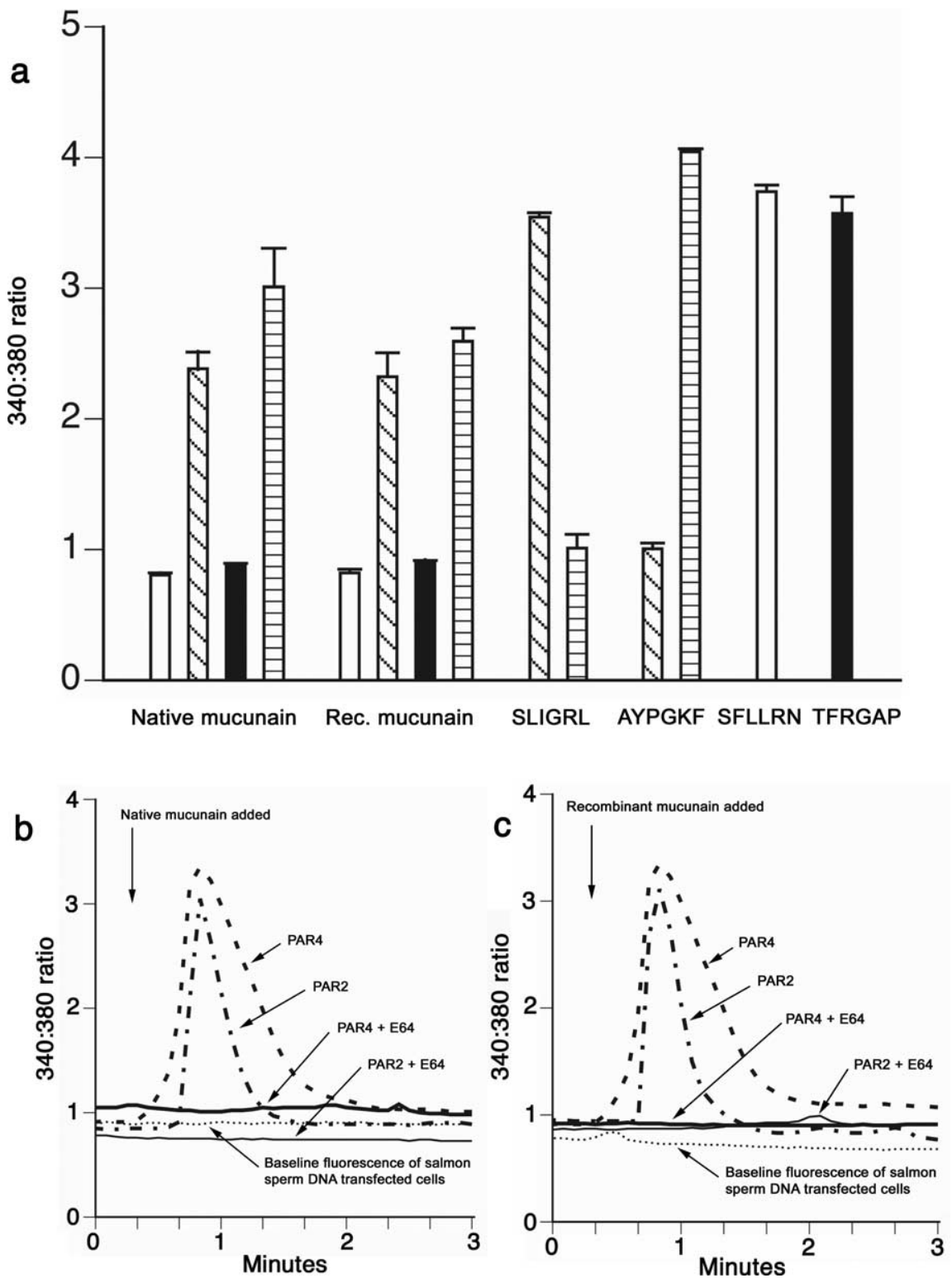

Figure 3. Native and recombinant mucunain induce responses in HeLa cells transfected with PAR receptors. $\boldsymbol{a}$, Mean peak response (mean peak 340:380 ratio) to the indicated protease of cells transfected with cDNAs encoding PAR1 (white bars), PAR2 (bars with angled lines), PAR3 (solid bars), and PAR4 (bars with horizontal lines). Mucunains were used at concentrations that yielded the greatest response: native mucunain, $0.3 \mu \mathrm{m}$; recombinant (Rec.) mucunain, $2 \mu \mathrm{m}$. Hexapeptides were all used at 1 $\mathrm{mm}$. The data from $10-20$ individual cells were averaged within a single experiment. The averages from at least three separate experiments were then combined and are presented $\pm S D . \boldsymbol{b}, \boldsymbol{c}$, Data from single-cell imaging. The curves demonstrate the effect of native $(\boldsymbol{b})$ and recombinant $(\boldsymbol{c})$ mucunain on PAR2 transfected cells and PAR4 transfected cells in the absence or presence of E64. Mucunain was added as indicated and remained present throughout the experiment. Concentrations of mucunain are as noted in $\boldsymbol{a}$. The concentration of E64 was $10 \mu \mathrm{m}$.

itch. Shelley and Arthur (1955) suggested that the active component, although not isolated, was a protease, which they named mucunain. Cowhage has been used recently to investigate sensory modalities and distinguish between histamine and nonhistamine pathways in humans and monkeys (Johanek et al., 2005, 2007; Davidson et al., 2007).

The present results reveal that the itch and nociceptive sensations evoked by cowhage are caused by a cysteine protease. We call this protease mucunain and have shown that it is a ligand for PAR2 and PAR4.

The protease-activated family of G-protein-coupled receptors includes four members, PAR1-PAR4. PAR1, PAR2, and PAR4 
have been implicated in inflammatory nociception, whereas PAR3 may form a dimer with PAR1 (McLaughlin et al., 2007). Proteases have long been linked to itch (Arthur and Shelley, 1955). It has been hypothesized, based on indirect evidence, that PAR2 receptors on itch-mediating nerve fibers may be activated by a serine protease released from mast cells (Steinhoff et al., 2003). Our findings are consistent with and extend these studies.

Elevated PAR2 in skin has been demonstrated in patients with atopic dermatitis (Steinhoff et al., 2003), but the expression in skin of PAR4 has not been reported in any condition and could be considered. Although the current study does not address the relative contribution of PAR2 and PAR4 activation to itch, we hypothesize, based on the calcium responses we observed, that mucunain has greater activity on PAR4 than it does on PAR2. A direct comparison between the intensity of sensations evoked by cowhage and tryptase has not been performed but could address this question. The results presented here provide a potentially important example of how a substance isolated from a plant may lead to insights into human physiology. Our findings suggest that it may be reasonable to consider the possibility that endogenous cysteine proteases contribute to itching via activation of both PAR2 and PAR4 receptors.

\section{References}

Arthur RP, Shelley WB (1955) The role of proteolytic enzymes in the production of pruritus in man. J Invest Dermatol 25:341-346.

Atanassoff PG, Brull SJ, Zhang J-M, Greenquist KW, Silverman DG, LaMotte RH (1999) Enhancement of experimental pruritus and mechanically evoked dysesthesias with local anesthesia. Somatosen Mot Res 16:299-303.

Barrett AJ, Kembhavi AA, Brown MA, Kirschke H, Knight CG, Tamai M, Hanada K (1982) L-trans-Epoxysuccinyl-leucylamido(4-guanidino)butane (E-64) and its analogues as inhibitors of cysteine proteinases including cathepsins B, H and L. Biochem J 201:189-198.

Bartoshuk LM, Duffy VB, Green BG, Hoffman HJ, Ko CW, Lucchina LA, Marks LE, Snyder DJ, Weiffenbach JM (2004) Valid across group comparisons with labeled scales: the gLMS versus magnitude matching. Physiol Behav 82:109-114.

Davidson S, Zhang X, Yoon CH, Khasabov SG, Simone DA, Giesler Jr GJ (2007) The itch-producing agents histamine and cowhage activate sepa- rate populations of primate spinothalamic tract neurons. J Neurosci 27:10007-10014.

Hwang HS, Chung HS (2002) Preparation of active recombinant cathepsins K expressed in bacteria as inclusion body. Protein Expr Purif 25:541-546.

Johanek LM, Shim B, Meyer RA, Ringkamp M (2005) Response of C-fiber nociceptors in monkey to different pruritic stimuli. Soc Neurosci Abstr 31:511.7.

Johanek LM, Meyer RA, Hartke T, Hobelmann JG, Maine DN, LaMotte RH, Ringkamp M (2007) Psychophysical and physiological evidence for parallel afferent pathways mediating the sensation of itch. J Neurosci 27:7490-7497.

Kauffman HF, Tamm M, Timmerman JA, Borger P (2006) House dust mite allergens Der $\mathrm{p} 1$ and Der $\mathrm{p} 5$ activate human airway-derived epithelial cells by protease-dependent and protease-independent mechanisms. Clin Mol Allergy 4:5.

Klein PA, Clark RA (1999) An evidence-based review of the efficacy of antihistamines in relieving pruritus in atopic dermatitis. Arch Dermatol 135:1522-1525.

Lourbakos A, Yuan YP, Jenkins AL, Travis J, Andrade-Gordon P, Santulli R, Potempa J, Pike RN (2001) Activation of protease-activated receptors by gingipains from Porphyromonas gingivalis leads to platelet aggregation: a new trait in microbial pathogenicity. Blood 97:3790-3797.

Masood K, Green BG, LaMotte RH (2005) Psychophysical measurements of pruritic and nociceptive sensations and dysesthetic states evoked by cutaneous application of cowhage spicules in human. Soc Neurosci Abstr 31:50.9.

McLaughlin JN, Patterson MM, Malik AB (2007) Protease-activated receptor-3 (PAR3) regulates PAR1 signaling by receptor dimerization. Proc Natl Acad Sci USA 104:5662-5667.

Schmelz M, Schmidt R, Bickel A, Handwerker HO, Torebjork HE (1997) Specific C-receptors for itch in human skin. J Neurosci 17:8003-8008.

Shelley WB, Arthur RP (1955) Mucunain, the active pruritogenic proteinase of cowhage. Science 122:469-470.

Shimada SG, Green BG, Zelterman D, LaMotte RH (2006) Itch exhibits spatial summation. Soc Neurosci Abstr 32:552.2.

Simone DA, Ngeow JY, Whitehouse J, Becerra-Cabal L, Putterman GJ, LaMotte RH (1987) The magnitude and duration of itch produced by intracutaneous injections of histamine. Somatosens Res 5:81-92.

Steinhoff M, Neisius U, Ikoma A, Fartasch M, Heyer G, Skov PS, Luger TA, Schmelz M (2003) Proteinase-activated receptor 2 mediates itch: a novel pathway for pruritus in human skin. J Neurosci 23:6176-6180.

Tuckett RP, Wei JY (1987) Response to an itch-producing substance in cat. II. Cutaneous receptor populations with unmyelinated axons. Brain Res 413:95-103. 